\title{
CHEMOSPHERE
}

\section{Degradation of 2-chlorophenol via a hydrogenotrophic biofilm under different reductive conditions}

\author{
Chao-Chien Chang ${ }^{a, *}$, Szu-Kung Tseng ${ }^{\mathrm{a}}$, \\ Chih-Cheng Chang ${ }^{b}$, Chun-Ming Ho ${ }^{c}$ \\ ${ }^{a}$ Graduate Institute of Environmental Engineering, National Taiwan University, 71 Chou Shan Road, Taipei 106, Taiwan \\ ${ }^{\mathrm{b}}$ Department of Environmental Resources Management, Transworld Institute of Technology, Chia-Tong Campus: 1221, \\ Jen-Nang Road, Douliu, Yunlin, Taiwan \\ ${ }^{\mathrm{c}}$ Department of Environmental Engineering, Tung Nan Institute of Technology, 92 Wan-Fu Hamlet, \\ Shen-Kun Village, Taipei, Taiwan
}

Received 11 June 2003; received in revised form 23 April 2004; accepted 25 April 2004

\begin{abstract}
This research studies the 2-chlorophenol (2-CP) degradation by the hydrogenotrophic biofilm cultivated in three silicone-tube membrane bioreactors under the conditions of denitrification (DN), sulfate-reduction (DS) and dechlorination (DC). Experimental results showed that after acclimation for more than four months with 2-CP, the respective 2-CP removal efficiency was $95 \%$ in DN, 94\% in DS and 95\% in DC reactors, under the condition of influent 2-CP 25 $\mathrm{mg} / \mathrm{l}$ with hydraulic retention time (HRT) of $15 \mathrm{~h}$. The metabolic pathway of 2-CP was different in different reactors. The 2-CP was thought to be utilized as carbon and energy source in DN and DS reactors, while the dechlorination occurred in the DC reactor in lack of nitrate and sulfate. The $\mathrm{pH}$ dramatically affected the 2-CP degradation in all reactors. Experimental results showed that the optimal $\mathrm{pH}$ range was around $6 \pm 0.2$ in DN, $7 \pm 0.2$ in DS, and 5.8-7.2 in DC reactors. Both nitrate and sulfate inhibited the 2-CP dechlorination, but the inhibition levels were different. Nitrate completely inhibited the dechlorination at once, while sulfate took a longer time to reach complete inhibition, only after the bacteria were adapted to the sulfate-reducing condition. Both inhibitions were accomplished by taking the place of 2-CP as electron acceptors. $\mathrm{H}_{2}$ served as an electron donor for dechlorination of 2-CP. The dechlorination was apparently stopped when lacking $\mathrm{H}_{2}$ and another pathway was responsible for the 2-CP degradation.
\end{abstract}

(c) 2004 Elsevier Ltd. All rights reserved.

Keywords: Dechlorination; Chlorophenol; Anaerobic; Hydrogenotrophic; Sulfate-reduction; Denitrification

\section{Introduction}

Microbial dechlorination is a common metabolic pathway for treating chlorophenol (CP) pollutants. Under anaerobic conditions, bacteria can dechlorinate various CPs to produce less-chlorinated phenol (Takeuchi et al., 2000). The dechlorination of CPs is usually stimulated by external organic compounds

\footnotetext{
${ }^{*}$ Corresponding author. Fax: +886-2-236-37-854.

E-mail address: grasschang@seed.net.tw (C.-C. Chang).
}

which act as electron donors (Hendriksen et al., 1992; Chang et al., 1996; Vallecillo et al., 1999). However, the residual external organic compounds are pollutants when used in groundwater remediation. For this reason, $\mathrm{H}_{2}$ is considered an electron donor to take the place of external organic compounds. Several researchers remarked that $\mathrm{H}_{2}$ could stimulate the dechlorination of the chlorinated organic compounds (DeWeerd et al., 1991; Distefano et al., 1992; Ballapragada et al., 1997; Warner et al., 2002). Regretfully, the dechlorination of CPs by hydrogenotrophic bacteria was not discussed in their papers. 
Nitrate and sulfate are common factors affecting the dechlorination. Several studies pointed out that the dechlorination of CPs was inhibited under the denitrification or the sulfate-reducing conditions (Madsen and Aamand, 1991; Puhakka et al., 1992; Häggblom et al., 1993; Chang et al., 1996, 1998). The metabolic pathway of CPs varies with the different reductive conditions. In denitrifying condition, CPs acted as electron donors and were degraded concomitantly with nitrate reduction (Puhakka et al., 1992; Bae et al., 2002a,b). However, there occurred two metabolic pathways in the sulfatereducing condition. The sulfate took the place of the CPs as an electron acceptor and inhibited the dechlorination. It appeared that the degradation of CPs was not through the dechlorination under this occasion (Häggblom and Young, 1990, 1995). In some cases, sulfate could stimulate the dechlorination of CPs. The sulfatereduction and dechlorination could proceed simultaneously under this condition. As the sulfate-reduction was inhibited, the dechlorination was also hindered (Kennes et al., 1996; Häggblom, 1998).

Although previous studies have mentioned the relations between nitrate/sulfate and the dechlorination of $\mathrm{CPs}$, the effects on the $\mathrm{CP}$ degradation under hydrogenotrophic denitrification and hydrogenotrophic sulfate-reduction still remain much to be discussed. So, this study utilized a gas-permeable silicone membrane reactor to cultivate a hydrogenotrophic biofilm for dechlorinating 2-CP. In order to further evaluate the $2-\mathrm{CP}$ biodegradation under different reductive conditions, three reactors were acclimated under the conditions of denitrifying, sulfate-reducing and dechlorinating. Also, the metabolic pathway of 2-CP by the hydrogenotrophic biofilm under different conditions was analyzed to clarify the role of $\mathrm{H}_{2}$ in the 2-CP degradation.

\section{Materials and methods}

\subsection{Bioreactor}

The gas-permeable silicone membrane bioreactor was made of glass with an effective volume of $850 \mathrm{ml}$. A silicone tube $(2.5 \mathrm{~mm}$ [i.d.] and $3.0 \mathrm{~mm}$ [o.d.] by $5.0 \mathrm{~m}$ long; Fuji system Co., Japan; approximate permeability for $\mathrm{H}_{2}$ was $6579 \times 10^{-10} \mathrm{cc} \mathrm{mm} \mathrm{s}^{-1} \mathrm{~cm}^{-2} \mathrm{cmHg}^{-1}$ ) was wound around the pillars in the reactor, as shown in Fig. 1. Anaerobic sludge from a swine wastewater treatment plant was immobilized by polyvinyl alcohol (PVA, Nacalai Tesque) and alginic acid (SIGMA) on the outside tube wall to form a biofilm (surface area approximately $\left.0.0471 \mathrm{~m}^{2}\right)$. The PVA $(16 \mathrm{~g})$ and alginic acid $(1.2 \mathrm{~g})$ with water $(100 \mathrm{ml})$ was mixed by stirring and heating, and then was mixed with $100 \mathrm{ml}$ of the anaerobic sludge. The mixture was coated on the silicone tube and soaked in the solidifying agent $\left(50 \% \mathrm{w} / \mathrm{v} \mathrm{NaNO}_{3}\right.$ and $2 \% \mathrm{w} / \mathrm{v} \mathrm{CaCl}_{2}$ ) for $1 \mathrm{~h}$. When the biofilm solidified around the silicone tube, it was extracted and rinsed with tap water (Hsieh et al., 2002). A cylinder was used to supply pure $\mathrm{H}_{2}$ to the lumen side of the silicone tube. The flow rate of $\mathrm{H}_{2}$ was arbitrarily set at $20 \mathrm{ml} \mathrm{min}^{-1}$ since the $\mathrm{H}_{2}$ diffusion efficiency was independent from

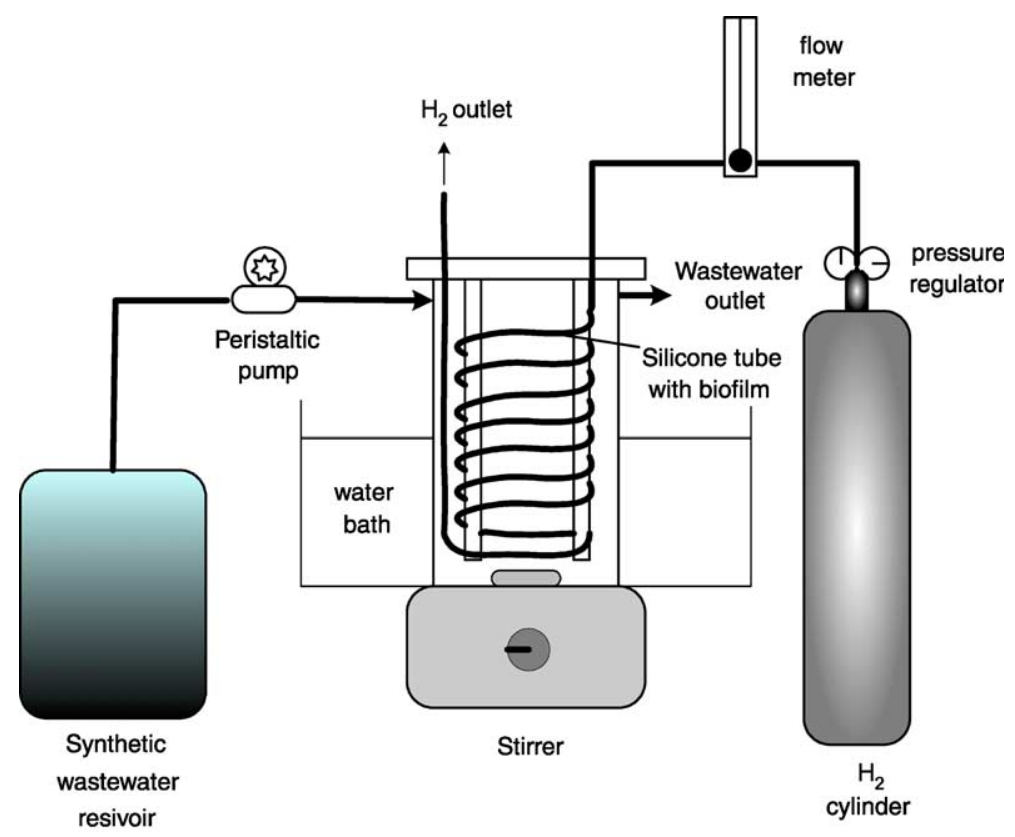

Fig. 1. Schematic diagram of the bioreactor. 
the flow rate. The measured $\mathrm{H}_{2}$ diffusion rate was $2.5 \mathrm{~g}$ $\mathrm{H}_{2} \mathrm{~m}^{-2}$ of the silicone tube wall (Ho et al., 2002).

\subsection{Acclimation}

Three reactors were acclimated by continuously feeding with synthetic wastewater. The synthetic wastewater contained $\mathrm{KH}_{2} \mathrm{PO}_{4}\left(1.0 \mathrm{gl}^{-1}\right), \mathrm{K}_{2} \mathrm{HPO}_{4}\left(1.0 \mathrm{gl}^{-1}\right)$, $\mathrm{NaHCO}_{3}\left(1.0 \mathrm{gl}^{-1}\right), \mathrm{MgCl}_{2}\left(20 \mathrm{mg} 1^{-1}\right), \mathrm{NH}_{4} \mathrm{Cl}(30 \mathrm{mg}$ $\left.\mathrm{N}^{-1}\right)$, trace elements $\left(1 \mathrm{mll}^{-1}\right)$ and $2-\mathrm{CP}$. The trace elements solution was comprised of $\mathrm{CaCl}_{2} \cdot \mathrm{H}_{2} \mathrm{O}$ (7.3 $\left.\mathrm{gl}^{-1}\right), \mathrm{MnCl}_{2} \cdot 4 \mathrm{H}_{2} \mathrm{O}\left(2.5 \mathrm{gl}^{-1}\right), \mathrm{CoCl}_{2} \cdot 6 \mathrm{H}_{2} \mathrm{O}\left(0.5 \mathrm{gl}^{-1}\right)$, $\left(\mathrm{NH}_{4}\right)_{6} \mathrm{Mo}_{7} \mathrm{O}_{24} \cdot 4 \mathrm{H}_{2} \mathrm{O} \quad\left(0.5 \mathrm{gl}^{-1}\right), \quad \mathrm{FeCl}_{2} \cdot 4 \mathrm{H}_{2} \mathrm{O} \quad(2.0$ $\left.\mathrm{gl}^{-1}\right), \mathrm{ZnCl}_{2}\left(1.0 \mathrm{gl}^{-1}\right)$ and $\mathrm{CuCl}_{2}\left(0.1 \mathrm{gl}^{-1}\right)$. The synthetic wastewater was deoxygenated by purging $\mathrm{N}_{2}$ for 5 min, and then 2-CP (Nakarai Chemicals, Ltd.) was added as the only organic compound. Potassium nitrate (50 $\mathrm{mg} \mathrm{N} \mathrm{1}^{-1}$ ) was added to one reactor to keep in denitrifying condition (DN reactor). And the sulfatereducing condition (DS reactor) was maintained by the addition of potassium sulfate ( $200 \mathrm{mg}^{-1}$ as sulfate). The dechlorinating condition (DC reactor) was in deficiency of nitrate and sulfate. The solution in the reactor was stirred by a magnetic stirrer bar, thus to form a complete mixing reactor. In addition, the bioreactor was kept in a water bath to ensure the temperature at $25^{\circ} \mathrm{C}$. The $\mathrm{pH}$ value of the reactor was manually adjusted with the $1 \mathrm{M}$ $\mathrm{HCl}$, or $1 \mathrm{M} \mathrm{NaOH}$ solution. The acclimation was started by continuously feeding the synthetic wastewater without the addition of 2-CP in the first 10 days. Then 2$\mathrm{CP}$ was added to the synthetic wastewater to the concentrations at $10 \mathrm{mgl}^{-1}$ during 11-20 days, $25 \mathrm{mgl}^{-1}$ during 21-30 days and $50 \mathrm{mgl}^{-1}$ during 31-50 days. During these periods, the hydraulic retention time (HRT) was controlled at $20 \mathrm{~h}$. Then, batch experiments were conducted to find the appropriate $\mathrm{pH}$ range during 51-86 days. After that, the reactors were operated under conditions of influent 2-CP concentration at $25 \mathrm{mg} \mathrm{l}^{-1}$ and HRT $15 \mathrm{~h}$. The 2-CP removal efficiency reached $95 \%$ in DN, $94 \%$ in DS and $95 \%$ in DC reactors after acclimated for more than four months.

\subsection{Experiments}

The batch experiments were conducted directly by the acclimated bioreactors with $\mathrm{H}_{2}$ at $20 \mathrm{ml} \mathrm{min}^{-1}$. In the beginning of each experiment, reactors were first emptied and $900 \mathrm{ml}$ of the fresh synthetic wastewater added. A $10 \mathrm{ml}$ sample was collected each time during a batch experiment period for analysis. The reactor was switched to the continuous-feeding mode after the experiment for recovering the activity of the biofilm. The immobilized biofilm could minimize the perturbation to the bacteria, so the biofilm activity could soon recover after the experiments. Another batch experiment was conducted with no $\mathrm{H}_{2}$ to examine the 2-CP degradation in the absence of $\mathrm{H}_{2}$. All the batch experimental results obtained in this study were the average of duplicate experiments.

The continuous-feeding experiments were run under the conditions of HRT of $15 \mathrm{~h}$ and influent 2-CP of 25 $\mathrm{mg}^{-1}$ (without replication). And the $\mathrm{pH}$ values of the reactors were controlled around 5.8-6.2 in DN, 6.8-7.2 in DS and 6.0-6.5 in DC reactors during continuousfeeding experiments. A $10 \mathrm{ml}$ sample was collected every 1-3 days for the analysis of 2-CP, phenol, nitrate and sulfate.

\subsection{Analytical methods}

Samples were collected and filtered through a 0.22 $\mu \mathrm{m}$ PVDF syringe filter (Millipore). The 2-CP and phenol were determined by high-performance liquid chromatography (HPLC, equipped with Millipore Model 501 pump, Waters 486 detector and a Polaris $5 \mathrm{u}$ C18-A column). The mobile phase was a mixture of acetonitrile, distilled water and acetate in the proportion of 500/500/5.7 (v/v). The HPLC pump was controlled at the flow rate of $1.0 \mathrm{ml} \mathrm{min}^{-1}$, and the UV detector was set at $254 \mathrm{~nm}$. Nitrate, nitrite and sulfate were determined by ion chromatography (Dionex DX-120) with mobile phase of $1.7 / 1.8 \mathrm{mM} \mathrm{NaHCO} / \mathrm{Na}_{2} \mathrm{CO}_{3}$ at a flow rate of $1.25 \mathrm{ml} \mathrm{min}^{-1}$. The total organic carbon (TOC) of the samples was determined by a total organic carbon analyzer (O.I. Analytical Model 1010). The oxidationreduction potential (ORP) was detected by the ORP meter (ORIGIN model 720A, USA), and the $\mathrm{pH}$ value was by the $\mathrm{pH}$ meter (HTC-200).

\section{Results and discussions}

\subsection{Variation of $p H$ and $O R P$ in the 2-CP batch degradation}

The relationships between 2-CP batch degradation, $\mathrm{pH}$ values and ORP values are shown in Fig. 2. The 2$\mathrm{CP}$ degrading rates were very similar in the three reductive conditions. They all revealed a marked degradation of the 2-CP on the first day and slowed down afterwards, as shown in Fig. 2a. The obvious declination of the 2-CP degrading rates in the beginning is relevant to the quick rise of the $\mathrm{pH}$ values. In Fig. $2 b$, the $\mathrm{pH}$ values quickly increased from the initial 7.0-8.2 in DN, 8.5 in DS and 7.7 in DC reactor on the first day, and then the $\mathrm{pH}$ values remained a slight increase along with the reaction time, which also corresponded to the retardation of the 2-CP degradation.

To further evaluate the $\mathrm{pH}$ effects on the 2-CP degradation, the reactors were operated in continuous-feeding mode and controlled at different $\mathrm{pH}$ range. Experimental results showed that the optimal $\mathrm{pH}$ range was around 


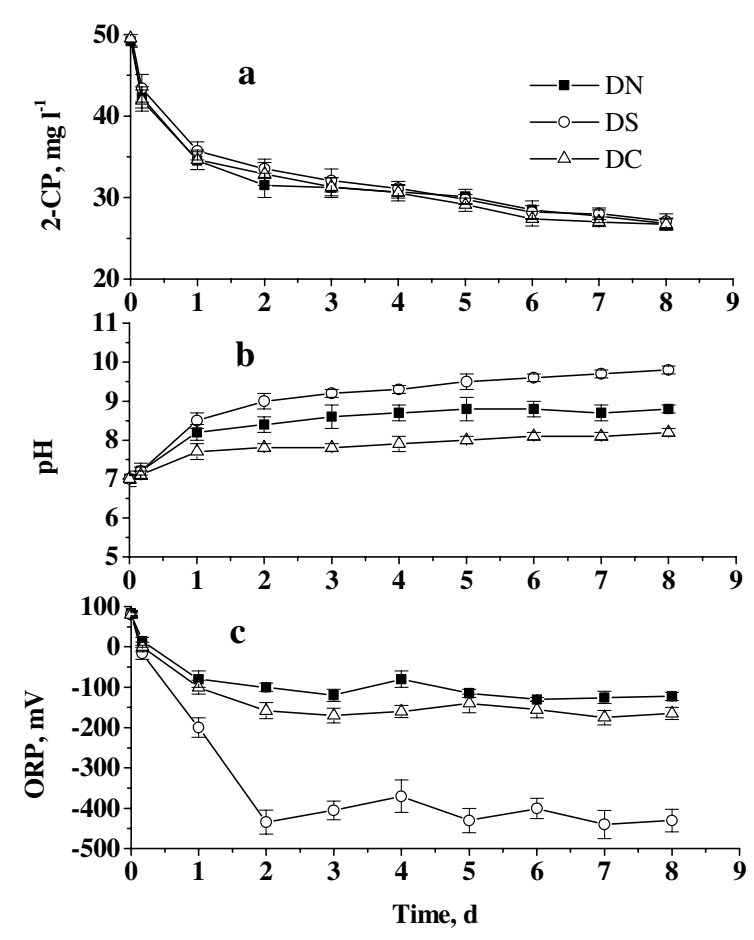

Fig. 2. The 2-CP degradation (a), the $\mathrm{pH}$ change (b) and the ORP change (c) in batch experiments of DN, DS and DC reactors (error bar represents the duplicate data range).

$6 \pm 0.2$ in DN, $7 \pm 0.2$ in DS, and 5.8-7.2 in DC reactors. It showed that the DC reactor could tolerate the changes of $\mathrm{pH}$ values better than the $\mathrm{DN}$ and $\mathrm{DS}$ reactors. When the $\mathrm{pH}$ value was beyond optimal ranges, the 2-CP removal efficiency would greatly decrease. For instance, the 2-CP removal efficiency in the reactors ranged from $92 \%$ to $96 \%$ at their optimal $\mathrm{pH}$ range, but it decreased to around $45-54 \%$ at $\mathrm{pH}$ value \pm 1 beyond the optimal range. This also accounted for the reason why the 2-CP degrading rate slowed down as the $\mathrm{pH}$ value increased in the batch experiment (Fig. 2a and b). By studying the microbial dechlorination of pentachlorophenol (PCP) in different $\mathrm{pH}$ conditions, Chang et al. (1998) also demonstrated that the dechlorination was greatly affected by $\mathrm{pH}$ values. In their research, the PCP dechlorination was completely inhibited as $\mathrm{pH}$ was below 6 or higher than 9.

The ORP is an indicator, which reflects the redox reactions in the environment. The ORP has been applied in activated sludge plants for keeping in good treatment efficiency for many years, especially for nitrogen removal (Charpentier et al., 1998). The ORP values for dechlorination of CPs are close to the value for denitrification. Besides, they are lower than that for $\mathrm{O}_{2}$ and much higher than the value for sulfate (Dolfing and Harrison, 1992). Fig. 2c demonstrates that ORP values decreased with the increasing reaction time and quickly turned to negative values on the first day, which implied the reductive reactions proceeding in the three reactors. Subsequently, the ORP values became stable after the second day, around $-100 \mathrm{mV}$ in $\mathrm{DN},-400 \mathrm{mV}$ in $\mathrm{DS}$ and $-150 \mathrm{mV}$ in DC reactors (Fig. 2c). The difference of ORP values indicated the various redox reactions proceeding in different reactors.

\subsection{Influence of nitrate and sulfate on 2-CP dechlorina- tion}

Batch experiments were conducted to evaluate the influence of nitrate and sulfate on 2-CP dechlorination in the DC reactor. Experimental results show that in the absence of nitrate and sulfate, the 2-CP degraded fastest (Fig. 3a), while the 2-CP degradation rate slowed down with the addition of nitrate or sulfate. In Fig. 3b, the production of the 2-CP dechlorinating intermediate, phenol, is exhibited. Without the addition of nitrate and sulfate, phenol was soon produced as 2-CP degraded. But phenol was not detected in the initial period $(0-5 \mathrm{~h})$ after the addition of sulfate at $50 \mathrm{mg}^{-1}$, and afterward, phenol was detected. The results showed that the addition of sulfate only decreased the dechlorinating rate (Fig. 3a) but not inhibited the dechlorination. The sulfate was almost not reduced within $32 \mathrm{~h}$ (Fig. 3d), showing that most sulfate could not be utilized as electron acceptors during this period. In the condition with nitrate $\left(50 \mathrm{mg} \mathrm{N}^{-1}\right)$, the 2-CP degradation was a little inhibited and phenol was only detected after $26 \mathrm{~h}$ (Fig. $3 a$ and b). Nitrate was found to decrease quickly through denitrification and completely depleted within $13 \mathrm{~h}$ (Fig. 3d). The dechlorination was thought to shift to the denitrification in the presence of nitrate because no phenol was detected under denitrifying condition. The decreasing TOC values also showed that the 2-CP was biodegraded and mineralized gradually (Fig. 3c). The decreasing rate of TOC had similar trend with the 2CP degradation. It indicated that nitrate and sulfate hindered the mineralization of 2-CP.

It is believed that shifting to the denitrifying or sulfate-reducing condition from the methanogenic condition can prevent the reductive dechlorination. In our experiment, the dechlorination of 2-CP was obviously inhibited by nitrate and sulfate, but their inhibition mechanisms were different. The dechlorination was entirely inhibited by the first addition of nitrate, which took the place of the 2-CP as an electron acceptor. So, phenol was not produced in the denitrifying period ( 0 $15 \mathrm{~h})$ and was detected in the nitrate depletion period $(24-42$ h) (Fig. 3b). However, the initial addition of sulfate decreased the 2-CP dechlorinating activity but not inhibited the dechlorination. A lag period was needed for the biofilm to adapt to the sulfate $(0-32 \mathrm{~h}$ in Fig. 3d). During this lag period, the increased salt con- 

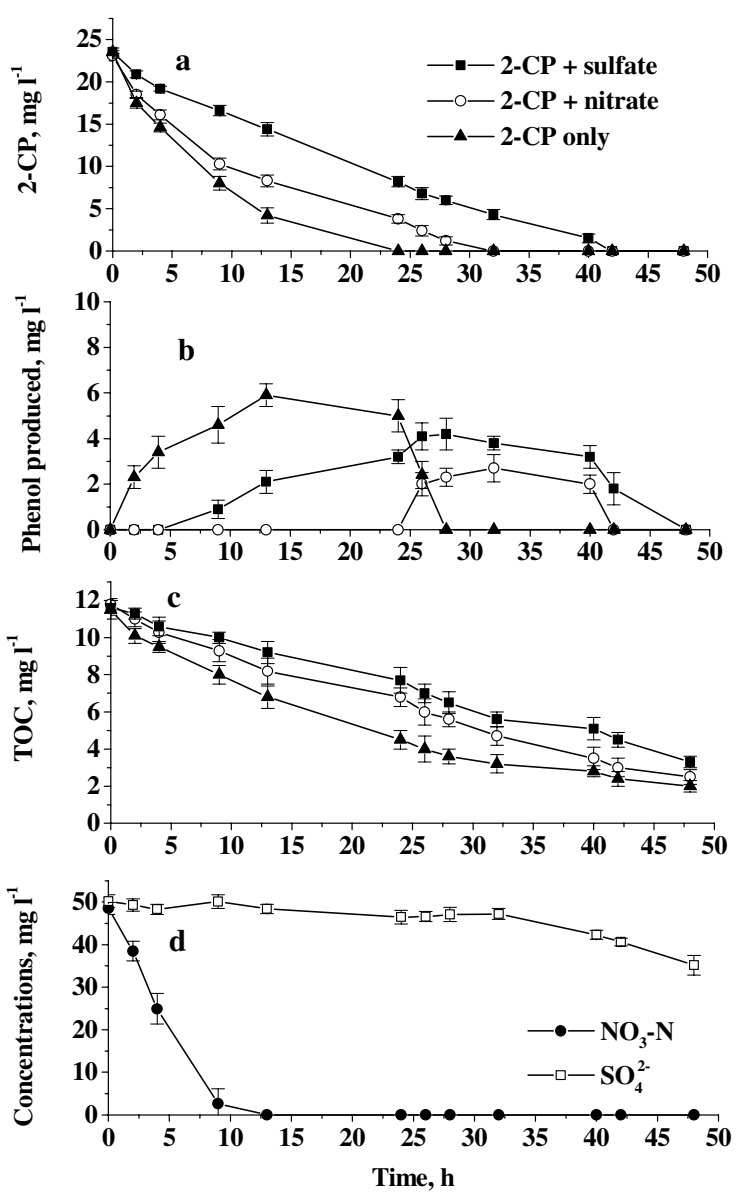

Fig. 3. The 2-CP degradation (a), the phenol produced (b), the TOC changes (c) and nitrate and sulfate-reduction (d) in batch experiments of DC reactor with either $\mathrm{NO}_{3}^{-}, \mathrm{SO}_{4}^{2-}$ or no additions (error bar represents the duplicate data range).

centration by the added potassium sulfate might be the cause to decrease the 2-CP dechlorinating rate. While in the period of dechlorination transferring to sulfatereduction (32-48 $\mathrm{h}$ in Fig. $3 \mathrm{a}$ and $\mathrm{d}$ ), the 2-CP dechlorination and the sulfate-reduction occurred simultaneously.

Under the hydrogenotrophic denitrifying condition, the 2-CP was thought to be utilized as carbon and energy source for bacteria growth. When 2-CP is used for denitrification, the theoretical nitrate to $2-\mathrm{CP}$ ratio $(\mathrm{N} / \mathrm{CP})$ is 5.2 , as shown below

$$
\begin{aligned}
& \mathrm{C}_{6} \mathrm{H}_{5} \mathrm{OCl}+5.2 \mathrm{NO}_{3}^{-}+4.2 \mathrm{H}^{+} \\
& \quad \rightarrow 6 \mathrm{CO}_{2}+2.6 \mathrm{~N}_{2}+\mathrm{Cl}^{-}+4.6 \mathrm{H}_{2} \mathrm{O}
\end{aligned}
$$

The N/CP ratio calculated by the nitrate and 2-CP consumption from our experimental results was 27.9, which was much higher than the theoretical N/CP ratio. It suggested that the denitrification was mainly catalyzed by $\mathrm{H}_{2}$ and the 2-CP degradation was not through denitrification. Otherwise, the degrading rate for 2-CP and TOC by denitrification should be much higher than it was according to its denitrifying rate.

Although the biodegrading pathway of 2-CP under hydrogenotrophic denitrification in this experiment was different from the previous studies, which presented that the degradation of CPs was concomitant with nitrate depletion under denitrifying condition (Puhakka et al., 1992; Häggblom et al., 1993; Bae et al., 2002a,b), the inhibition mechanism for dechlorination by nitrate was the same. The inhibition was mainly achieved through the shifting of the electron acceptor from CPs to nitrate.

\subsection{Competition of nitrate, sulfate and 2-CP in different reactors}

The batch degradation of nitrate, sulfate and 2-CP in reactors acclimated by different conditions is illustrated in Fig. 4. In the reactor acclimated by denitrifying condition, nitrate was utilized as an electron acceptor and soon depleted in the beginning (Fig. 4a). Sulfate began to decrease at about $30 \mathrm{~h}$, almost after the complete depletion of nitrate. During this period, the 2-CP dechlorinating intermediate, phenol, was detected (Fig. 4a) - an indication that the sulfate did not completely inhibit the dechlorination as observed before (Fig. 3).
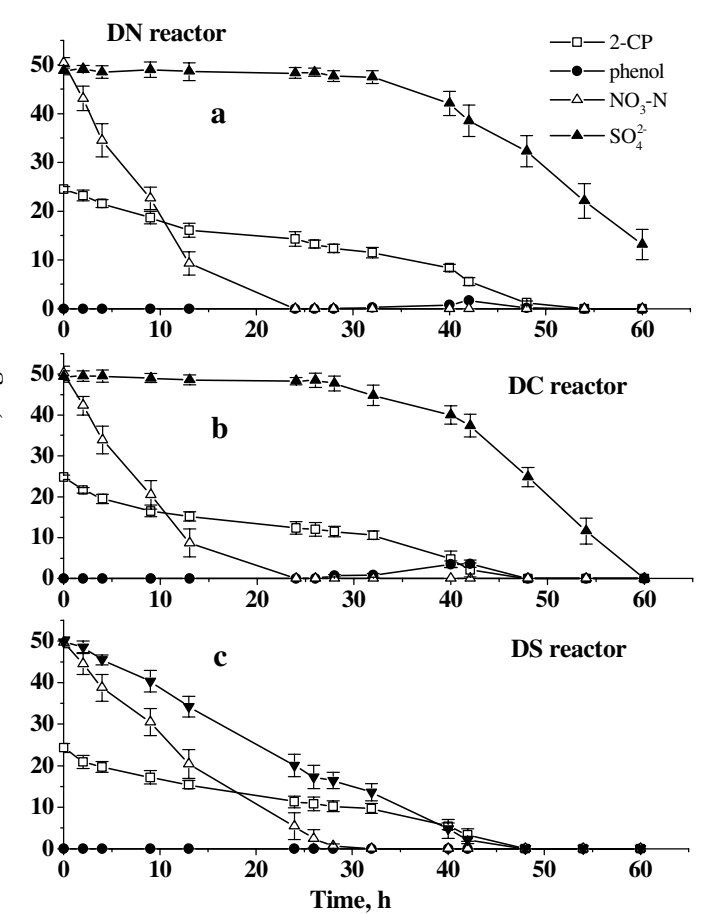

Fig. 4. Batch experiments of DN reactor (a), DS reactor (b) and $\mathrm{DC}$ reactor (c) in the presence of $2-\mathrm{CP}$, nitrate and sulfate simultaneously (error bar represents the duplicate data range). 
The result in DC reactor was similar to that in DN reactor, as shown in Fig. 4b. Even though the DC reactor was not acclimated to nitrate, the nitrate depletion rate was as rapid as that in the DN reactor (Fig. 4a and $b$ ). Phenol also appeared after the denitrifying period (Fig. 4b). The variation of sulfate concentrations revealed an adaptation period for sulfate-reduction in $\mathrm{DC}$ reactor. The results of the $\mathrm{DN}$ and $\mathrm{DC}$ reactors also showed that nitrate rather than 2-CP and sulfate was the prior electron acceptor. If nitrate was present in the reactor, the denitrification was the predominant metabolic pathway. The hydrogenotrophic bacteria could also utilize sulfate as an electron acceptor, but it took a longer time for the adaptation to the sulfate-reducing condition. During the adapting period, bacteria could use both 2-CP and sulfate as electron acceptors. So, the dechlorination and sulfate-reduction could simultaneously occur in DN and DC reactors (Fig. 4a and b). Although previous studies have suggested that sulfatereducing bacteria (SRB) were capable for dechlorinating CPs (Häggblom and Young, 1990; Kennes et al., 1996; Häggblom, 1998), whether the dechlorination and sulfate-reduction were catalyzed by the same bacteria was still uncertain. But even though sulfate only partially inhibited the production of phenol, it was believed that sulfate could entirely take the place of 2-CP as an electron acceptor after the bacteria adapted to the sulfatereducing condition.

The results obtained from the DS reactor, however, were different from those of the other two reactors (Fig. $4 c)$. Nitrate, sulfate and 2-CP were found to decay almost at the same time, and among them, the decay of nitrate was the fastest. Also, the sulfate-reducing ability in DS reactor was higher than that in DN and DC reactors. The sulfate-reduction occurred immediately after the addition of sulfate in DS reactor, unlike the DN and DC reactors with a lag period for sulfatereduction (Fig. 4a and b). Phenol was not detected during this experiment. It might be caused by the reason that the denitrification and sulfate-reduction took the place of 2-CP dechlorination. Also, the sulfate-reduction was mainly catalyzed by $\mathrm{H}_{2}$ and the 2-CP degradation was not through sulfate-reduction, because no sulfate was reduced when stopping the $\mathrm{H}_{2}$ supply (Section 3.5).

In short, nitrate and sulfate could compete $2-\mathrm{CP}$ as an electron acceptor for the hydrogenotrophic biofilm. When the denitrification or sulfate-reduction was proceeding, the dechlorination would be stopped. When nitrate or sulfate existed, nitrate would immediately take the place of 2-CP as an electron acceptor without adaptation. But sulfate often required a longer time for the adaptation of bacteria in reactors not adapted to sulfate-reduction. As the bacteria adapted to the sulfatereducing environment, sulfate could replace $2-\mathrm{CP}$ as an electron acceptor and the 2-CP might be utilized as carbon and energy source. This situation conflicted the theory of redox reaction where the redox potential of 2CP was much higher than that of sulfate (Dolfing and Harrison, 1992). The 2-CP should theoretically more easily be an electron acceptor than sulfate. However, sulfate would take the place of 2-CP as the electron acceptor by bacteria adapted to the sulfate-reduction. This phenomenon should be cause by the activity of microbial enzyme.

\subsection{Dynamic effects of different nitrate and sulfate concentrations}

The results of the continuous-feeding with different nitrate concentrations in the DC reactor within 28 days are revealed in Fig. 5a. The nitrate concentration was 0 $\mathrm{mg} \mathrm{N}{ }^{-1}$ in $0-7$ days, $25 \mathrm{mg} \mathrm{N}^{-1}$ in 7-14 days, $50 \mathrm{mg} \mathrm{N}$ $1^{-1}$ in 14-21 days, and $100 \mathrm{mg} \mathrm{N}^{-1}$ in $21-28$ days. The effluent 2-CP concentration increased on the eighth day after the addition of $25 \mathrm{mg} \mathrm{N}^{-1}$ nitrate, suggesting the inhibition of 2-CP degradation. However, the effluent 2$\mathrm{CP}$ concentration quickly restored to the original level on the 12th day and was not detected after the 14th day. The restoration of 2-CP removal indicated that bacteria had adapted to a new metabolic pathway. Under this situation, even the higher influent nitrate concentrations at 50 and $100 \mathrm{mg} \mathrm{N}^{-1}$ would not affect the 2-CP degradation (Fig. 5a).

Fig. $5 b$ shows the different influent sulfate concentrations and their effects: $0-5$ day $\left(0 \mathrm{mgl}^{-1}\right), 5-17$ day (50 $\left.\mathrm{mg}^{-1}\right), 17-25$ day $\left(100 \mathrm{mg}^{-1}\right)$ and $25-33$ day (200 $\mathrm{mg}^{-1}$ ). After the first addition of sulfate on fifth day, the effluent 2-CP concentration gradually increased and reached a peak, $8.7 \mathrm{mgl}^{-1}$, on the ninth day. Then, the concentration gradually decreased to the original level on around 15th day. Different from nitrate, the addition of higher sulfate concentration (100 and $200 \mathrm{mg} \mathrm{l}^{-1}$ ) also caused a rise of the effluent 2-CP. But their influences were minor compared with the first sulfate addition and, also, restored faster.

As mentioned, the metabolic pathway would shift from the dechlorination to the denitrification in the presence of nitrate or to the sulfate-reducing reaction in the presence of sulfate. Namely, the increase of effluent 2-CP after the addition of nitrate or sulfate was caused by the change of metabolic pathway. When the environment was first changed to the denitrifying condition, the 2-CP degrading efficiency decreased because bacteria had not yet adapted to the new metabolic pathway. After the bacteria adapted to the new metabolic pathway, the 2-CP degrading efficiency increased and was even higher than that by dechlorinating pathway (Fig. 5a). The changes from dechlorination to sulfate-reduction showed a similar effect on 2-CP degradation. The only difference was that it took longer time for bacteria to adapt to the sulfate-reducing condition. The result 


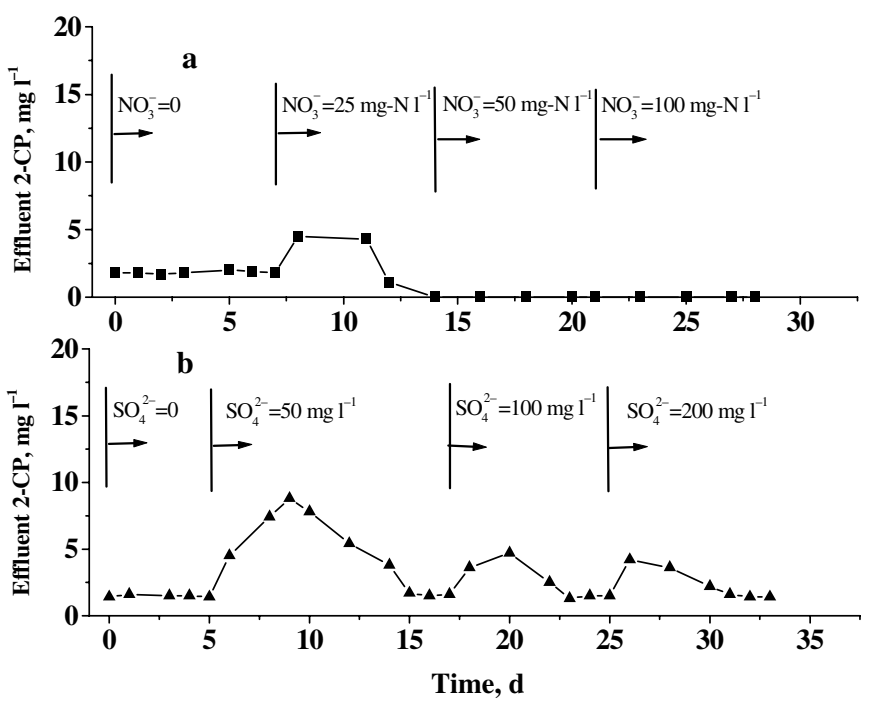

Fig. 5. Effluent 2-CP of DC reactor operated in continuous-feeding mode under different influent concentrations of nitrate (a) and sulfate (b).

corresponded to our earlier experiment; that is, nitrate was much easier to be utilized as an electron acceptor than sulfate (Fig. 4).

\section{5. $\mathrm{H}_{2}$ in the 2-CP degradation}

A continuous-feeding experiment was conducted to examine the role of $\mathrm{H}_{2}$ in the 2-CP degradation. The reactors were kept in conditions of supplying $\mathrm{H}_{2}$, influent 2-CP at $25 \mathrm{mgl}^{-1}$ and the HRT $15 \mathrm{~h}$ before this run. As soon as the $\mathrm{H}_{2}$ supply was stopped, the run started, and again supplied with $\mathrm{H}_{2}$ on the 12th day.

Experimental results showed that the initial effluent 2-CP concentrations were around $0.5-1.8 \mathrm{mgl}^{-1}$, and immediately increased after stopping the $\mathrm{H}_{2}$ supply, as shown in Fig. 6a. The effluent 2-CP in DS reactor increased to $12.8 \mathrm{mgl}^{-1}$, and, meanwhile, the sulfate removal efficiency dropped from $69 \%$ to $0 \%$ (Fig. 6b). It demonstrated that the 2-CP degradation and sulfatereduction were severely hindered as the $\mathrm{H}_{2}$ supply stopped, however, inhibition of 2-CP degradation was transient. This phenomenon was also found in DN reactor whose 2-CP degradation and nitrate removal efficiency rapidly dropped when lacking $\mathrm{H}_{2}$ (Fig. 6a,b). The effluent 2-CP concentrations also increased on the next day but reached the original levels on the second day in DC reactor (Fig. 6a). Furthermore, the effluent 2$\mathrm{CP}$ was not detected on the third day after stopping $\mathrm{H}_{2}$. The change of the effluent 2-CP concentration also showed that the metabolic pathway of 2-CP was changed by $\mathrm{H}_{2}$. When re-supplied with $\mathrm{H}_{2}$ on the 12th day, the effluent 2-CP increased again the next day and gradually restored several days later (Fig. 6a). The
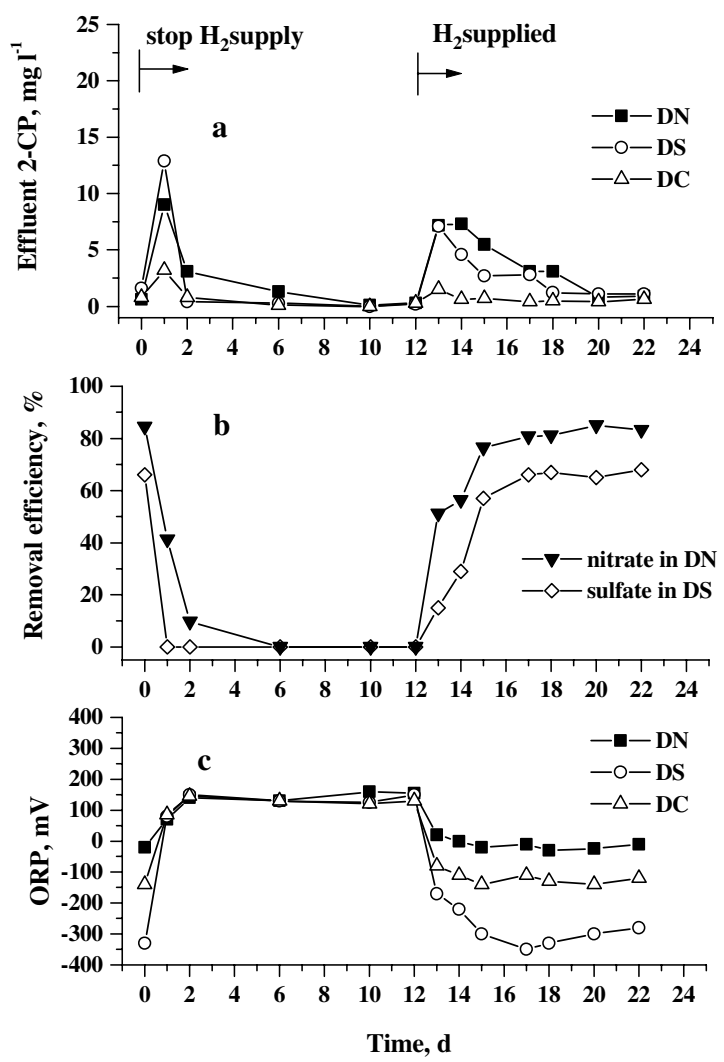

Fig. 6. The detected water quality of reactors with the change of $\mathrm{H}_{2}$ supply under continuous-feeding mode. (a) The effluent 2$\mathrm{CP}$ of DN, DS and DC reactors, (b) the nitrate and sulfate removal efficiency in DN and DS reactors, respectively, and (c) the ORP value in DN, DS and DC reactors. 
nitrate and sulfate removal efficiency in the DN and DS reactors also rapidly increased when supplied with $\mathrm{H}_{2}$ and reached a stable condition after the 17th day (Fig.6b). The phenol was always not detected in all reactors during this experiment, because it would be soon degraded as if it was derived from 2-CP under the continuous-feeding operation.

The ORP values in the reactors also changed along with the $\mathrm{H}_{2}$ supply. When the $\mathrm{H}_{2}$ supply was stopped, the ORP values in the DN, DS and DC reactors increased from around $-50,-330$ and $-140 \mathrm{mV}$ to about $+130 \mathrm{mV}$, respectively (Fig. 6c). However, the ORP decreased to the original level when re-supplied with $\mathrm{H}_{2}$. As mentioned before, the different ORP values implied different metabolic pathways occurring in the reactors. The ORP changes indicated that the reducing reactions were controlled by $\mathrm{H}_{2}$. When the $\mathrm{H}_{2}$ supply was stopped or re-supplied, the biodegrading pathway for 2-CP changed and caused the increase of effluent 2-CP concentrations (Fig. 6a). Although the 2-CP degradation in DC reactor was only slightly affected by $\mathrm{H}_{2}$, the metabolic pathways for 2-CP with or without $\mathrm{H}_{2}$ were different greatly. The 2-CP degradation in DC reactor was through the reductive dechlorination with $\mathrm{H}_{2}$ as an electron donor (as shown in Fig. 3), while another metabolic pathway was responsible for 2-CP degradation in the lack of $\mathrm{H}_{2}$. A further batch experiment was conducted with no $\mathrm{H}_{2}$ supply, which showed that no phenol was produced as 2-CP degraded (results not shown). The 2-CP might be degraded through fermentation in the condition without $\mathrm{H}_{2}$. When in the lack of $\mathrm{H}_{2}$, the 2-CP was the only electron donor to support the bacteria growth in all reactors. Hence, the 2-CP degradation was even faster than that with $\mathrm{H}_{2}$ as the electron donor (Fig. 6a).

It was obvious that $\mathrm{H}_{2}$ served as an electron donor for the denitrification, sulfate-reduction and 2-CP dechlorination in the reactors. Although 2-CP would also be degraded without the supply of $\mathrm{H}_{2}$, our study demonstrated that $\mathrm{H}_{2}$ could be effectively utilized for dechlorination in lack of external organic compounds. The dechlorinating ability of our hydrogenotrophic bioreactor might be effectively applied to the dechlorination of other chlorinated organic compounds.

\section{Conclusions}

This study demonstrated the 2-CP dechlorinating ability of the hydrogenotrophic biofilm and clarified the 2-CP degradation under different reductive conditions. The following conclusions can be drawn from the research:

1. Biodegradation of 2-CP was greatly affected by $\mathrm{pH}$ values. The bacteria of the DC reactor exhibited a better tolerance for $\mathrm{pH}$ change than those of $\mathrm{DN}$ and DS reactors. The optimal $\mathrm{pH}$ ranges were around $6.0 \pm 0.2$ in $\mathrm{DN}, 7.0 \pm 0.2$ in DS, and 5.8-7.2 in DC reactors.

2. In the hydrogenotrophic bioreactor system, the 2-CP dechlorination was affected by nitrate and sulfate. When nitrate or sulfate existed in the environment for a long period, bacteria would be acclimated to utilize nitrate or sulfate as an electron acceptor. In this situation, the 2-CP dechlorination shifted to the denitrification or sulfate-reducing reaction.

3. The competition of different electron acceptors by the hydrogen bacteria demonstrated that nitrate was the more preferred electron acceptor than sulfate and 2$\mathrm{CP}$. Although the chemical reaction for the 2-CP reduction should superior to the sulfate-reduction, the 2-CP could not compete with sulfate as an electron acceptor when bacteria were adapted to the sulfate-reduction.

4. The metabolic pathway of 2-CP by the hydrogenotrophic biofilm varied with different reductive conditions. In the environment without nitrate and sulfate, the 2-CP was first dechlorinated to phenol and then further degraded. While the 2-CP was thought to be utilized as carbon and energy source under the denitrifying and sulfate-reducing conditions.

5. $\mathrm{H}_{2}$ was a crucial factor in keeping the reactors in reductive conditions and acted as an electron donor for dechlorination of 2-CP, denitrification and sulfate-reduction. This proved that $\mathrm{H}_{2}$ could take the place of external organic compounds for dechlorinating 2-CP and might be applied to the treatment of other chlorinated organic compounds.

\section{References}

Bae, H.S., Yamagishi, T., Suwa, Y., 2002a. Evidence for degradation of 2-chlorophenol by enrichment cultures under denitrifying conditions. Microbiology 148, 221227.

Bae, H.S., Yamagishi, T., Suwa, Y., 2002b. Developing and sustaining 3-chlorophenol-degrading populations in up-flow anaerobic column reactors under circum-denitrifying conditions. Appl. Microbiol. Biotechnol. 59, 118-124.

Ballapragada, B.S., Stensel, H.D., Puhakka, J.A., Ferguson, J.F., 1997. Effect of hydrogen on reductive dechlorination of chlorinated ethenes. Environ. Sci. Technol. 31, 1728-1734.

Chang, B.V., Zheng, J.X., Yuan, S.Y., 1996. Effects of alternative electron donors, acceptors and inhibitors on pentachlorophenol dechlorination in soil. Chemosphere 33, 313-320.

Chang, B.V., Chiang, C.W., Yuan, S.Y., 1998. Dechlorination of pentachlorophenol in anaerobic sewage sludge. Chemosphere 36, 537-545.

Charpentier, J., Martin, G., Wacheux, H., Gilles, P., 1998. ORP regulation and activated sludge: 15 years of experience. Water Sci. Technol. 38, 197-208. 
DeWeerd, K.A., Concannon, F., Suflita, J.M., 1991. Relationship between hydrogen consumption, dehalogenation, and the reduction of sulfur oxyanions by Desulfomonile tiedjei. Appl. Environ. Microbiol. 57, 1929-1934.

Distefano, T.D., Gossett, J.M., Zinder, S.H., 1992. Hydrogen as an electron donor for dechlorination of tetrachloroethene by an anaerobic mixed culture. Appl. Environ. Microbiol. 58, 3622-3629.

Dolfing, J., Harrison, B.K., 1992. Gibbs free energy of formation of halogenated aromatic compounds and their potential role as electron acceptors in anaerobic environments. Environ. Sci. Technol. 26, 2213-2218.

Häggblom, M.M., 1998. Reductive dechlorination of halogenated phenols by a sulfate-reducing consortium. FEMS Microbiol. Ecol. 26, 35-41.

Häggblom, M.M., Young, L.Y., 1990. Chlorophenol degradation coupled to sulfate reduction. Appl. Environ. Microbiol. $56,3255-3260$.

Häggblom, M.M., Young, L.Y., 1995. Anaerobic degradation of halogenated phenols by sulfate-reducing consortia. Appl. Environ. Microbiol. 61, 1546-1550.

Häggblom, M.M., Rivera, M.D., Young, L.Y., 1993. Influence of alternative electron acceptors on the anaerobic biodegradability of chlorinated phenols and benzoic acids. Appl. Environ. Microbiol. 59, 1162-1167.

Hendriksen, H.V., Larsen, S., Ahring, B.K., 1992. Influence of a supplemental carbon source on anaerobic dechlorination of pentachlorophenol in granular sludge. Appl. Environ. Microbiol. 58, 365-370.
Ho, C.M., Tseng, S.K., Chang, Y.J., 2002. Autotrophic denitrification via a biofilm growing on a gas-permeable silicone tube. J. Chin. Inst. Environ. Eng. 12, 307-313.

Hsieh, Y.L., Tseng, S.K., Chang, Y.J., 2002. Nitrification using polyvinyl alcohol-immobilized nitrifying biofilm on an $\mathrm{O}_{2}$ enriching membrane. Biotechnol. Lett. 24, 315-319.

Kennes, K., Wu, W.M., Bhatnagar, L., Zeikus, J.G., 1996. Anaerobic dechlorination and mineralization of PCP and 2,4,6-TCP by methanogenic PCP-degrading granules. Appl. Microbiol. Biotechnol. 44, 801-806.

Madsen, T., Aamand, J., 1991. Effect of sulfuroxy anions on degradation of pentachlorophenols by a methanogenic enrichment culture. Appl. Environ. Microbiol. 57, 24532458.

Puhakka, J.A., Shieh, W.K., Järvinen, K., Melin, E., 1992. Chlorophenol degradation under oxic and anoxic conditions. Water Sci. Technol. 25 (1), 147-152.

Takeuchi, R., Suwa, Y., Yamagishi, T., Yonezawa, Y., 2000. Anaerobic transformation of chlorophenols in methanogenic sludge unexposed to chlorophenols. Chemosphere 41, 1457-1462.

Vallecillo, A., Garcia-Encina, P.A., Peña, M., 1999. Anaerobic biodegradability and toxicity of chlorophenols. Water Sci. Technol. 40, 161-168.

Warner, K.A., Gilmour, C.C., Capone, D.G., 2002. Reductive dechlorination of 2,4-dichlorophenol and related microbial processed under limiting and non-limiting sulfate concentration in anaerobic mid-Chesapeake Bay sediments. FEMS Microbiol. Ecol. 40, 165-195. 